\title{
European ceramic technology in the Far East: enamels and pigments in Japanese art from the 16th to the 20th century and their reverse influence on China
}

\author{
Riccardo Montanari ${ }^{* *}$ D, Nobuyuki Murakami², Philippe Colomban³ ${ }^{3}$ Maria Francesca Alberghina ${ }^{4}$, \\ Claudia Pelosi ${ }^{5}$ and Salvatore Schiavone ${ }^{4}$
}

\begin{abstract}
The production of Japanese enamels for porcelain decoration was thought to have originated from the direct and exclusive influence of Chinese potters who moved to Japan during the chaotic Ming to Qing dynastic change in 1644. Recent systematic studies have identified, for the first time, the crucial influence of Jesuit missionaries on pigment and enamel production in Japan from the late 16th-century. In particular, such first encounter laid the foundation for the continued influence exerted by European technology on Japanese art throughout the centuries. The present study has further identified European enamels used for the decoration of polychrome wares fired in Arita, the porcelain production center of Japan. This continued exchange not only marked the Edo period, but also extended into the twentieth century. For the first time, the lack of written records regarding the use of western pigments for enamel production caused by the persecutions of European and Japanese Christians has been overcome in the work herein presented. The nature of the imported materials has been firmly identified and characterized. The analytical results (EDXRF and Raman) have finally revealed how western technology and materials not only kept influencing Japanese art during the isolation (sakoku) period, but also accompanied the strong westernization process that marked Japanese history from the late nineteenth century. Moreover, the significant reverse influence of Japanese-made enamels on Chinese polychrome porcelain production in the late Qing and twentieth century has been fully identified for the first time. Furthermore, results show that the shift of the Pb mode of lead antimonate (Naples Yellow) is affected by the firing temperature for enamel decoration, and that this characteristic, along with the chemical composition, enables the identification of the origin and manufacture period of the yellow enamel.
\end{abstract}

Keywords: Porcelain, Enamel, Pigment, Painting, Japan, Jesuit, Seminario, China, EDXRF, Raman

\section{Introduction and historical context}

The production of overglaze enamels in Japan was long thought to have originated from the direct and exclusive influence of Chinese potters in the mid seventeenth century $[1,2]$ when the collapse of the Ming dynasty

\footnotetext{
*Correspondence: ckrm97@yahoo.com

${ }^{1}$ Independent Researcher, Expert Witness, Rome, Italy

Full list of author information is available at the end of the article
}

caused many of them to flee to Japan to find new profitable markets for their own survival. Yet, recent systematic studies on the origin of the materials employed for polychrome decoration identified, for the first time, the technological exchange that occurred between Jesuit missionaries and Japanese painters and potters from the late sixteenth century [3, 4]. In particular, the European Renaissance practice of using the same coloring agents both for paintings and ceramics was unquestionably confirmed by the matching compound detected on a
Springer Open

(0) The Author(s) 2020. This article is licensed under a Creative Commons Attribution 4.0 International License, which permits use, sharing, adaptation, distribution and reproduction in any medium or format, as long as you give appropriate credit to the original author(s) and the source, provide a link to the Creative Commons licence, and indicate if changes were made. The images or other third party material in this article are included in the article's Creative Commons licence, unless indicated otherwise in a credit line to the material. If material is not included in the article's Creative Commons licence and your intended use is not permitted by statutory regulation or exceeds the permitted use, you will need to obtain permission directly from the copyright holder. To view a copy of this licence, visit http://creativeco mmons.org/licenses/by/4.0/. The Creative Commons Public Domain Dedication waiver (http://creativecommons.org/publicdomain/ zero/1.0/) applies to the data made available in this article, unless otherwise stated in a credit line to the data. 
coloured porcelain and a European style painting created by a Japanese painter who studied at the Jesuit Seminario under the direction of the Italian Jesuit painter Giovanni Cola from 1583 [4]. The production of sacred and secular images based on models imported from Europe, be it prints, engravings or paintings, involved the use of European pigments that did not exist in Japan at the time [3-6]. These new pigments also marked Chinese enamel production from the early eighteenth century, after Jesuit missionaries were ordered by the Kangxi Emperor in 1695 to establish a glass workshop in the Palace to reproduce the enamels of western origin that had strongly impressed him [7, 8]. Recently, Raman analyses have confirmed the use of European enamel precursors at the end of Kangxi reign as mentioned in historical records $[9,10]$. This pattern of influence had actually originated in Japan in the late sixteenth century $[3,4]$. Additional evidence comes from Naito Tokuen Johan [11], a Christian samurai and close friend of Takayama Ukon, who supported the establishment of a glass workshop in the painting Seminario built by the Jesuits in Arie in 1595 under the supervision of Giovanni Cola [11]. The Jesuit Seminario was attended by Japanese and Chinese painters eager to learn European oil painting techniques [12]. The imported compounds employed for such purpose were scarce and very expensive [6], so their use was strictly allowed to those having trained under the direct supervision of Giovanni Cola himself. In particular, tin and antimony were important elements used in Renaissance Europe for enameling of majolica [13-16], Limoges metal wares [17], and for preparing painting pigments $[18,19]$. Both end-members of pyrochlore solid solutions (lead-tin yellow and lead antimonate yellow) as well as more complex solid solutions had been largely used since Roman times [20-22].

These same pigments have been detected on the famous Painting of the Madonna with the Infant Jesus and Her Fifteen Mysteries (1620 s, Japan) [5] and on the rare mukozuke dish bearing the Japanese mark 'Kan'ei Nen Sei' (made in the Kan'ei period, that is 1624-1644) [3]. Those instances have provided the definitive proof that the first phase of technological exchange between Europe and Japan started in the late sixteenth century, and that it continued until the final expulsion of all Christians by the Tokugawa Shogunate in 1639 as a result of the strictly enforced persecutions, with no surviving documents relating to the Jesuit presence and the early interaction with the Japanese. This study has proven, for the first time, how such first technological exchange between Jesuit missionaries and the Japanese in the sixteenth century laid the foundation for the continued influence exerted by Europeans on Japanese applied arts (porcelain, prints, and paintings) throughout the Edo period (16031868 ) and into the twentieth century.

We report here a non-destructive analysis carried out by X-Ray Fluorescence (ED-XRF) and Raman spectroscopy in order to get more information on the use of these ceramic pigments, thus overcoming the daunting issue of the lack of written records regarding the use of western pigments and/or western technology for enamel production. Shards of polychrome decorated porcelains fired in Arita, the porcelain production center of Japan, dating from the nineteenth and twentieth century, were analyzed with the aim of identifying the coloring agents employed for such production. The results have finally provided a definitive answer, revealing how western technology and materials not only kept influencing Japanese art during the isolation (sakoku) period, but also accompanied the strong westernization process of the country that marked Japanese craft and industry from the late nineteenth century.

\section{Materials and methods Analyzed shards}

All analyzed shards were provided by the Arita Museum of History, Arita, Saga Prefecture, Japan, and were mostly excavated at the Aka-e machi site (enamellers' quarter) located in the Uchiyama area of Arita, where all enamellers had been moved by the Nabeshima clan in the late 1650s in order to improve the production process through better labor organization [4]. The shards provide crucial information regarding the coloring agents and enamel preparation techniques employed when the presence of western countries increased significantly and the Tokugawa shogunate was about to collapse. Characteristics are summarized in Fig. 1.

\section{XRF spectrometer: experimental and measurement parameters}

The employed XRF portable instrument consists of a miniature X-ray tube system (Amptek, X-123 SDD, Mini-X $\mathrm{X}$-ray tube, USA) which includes the X-ray tube (max voltage of $40 \mathrm{kV}$, max current of $0.2 \mathrm{~mA}$, target Rh, collimator 1 or $2 \mathrm{~mm}$ ), the power supply, the control electronics and the USB communication for remote control; a Silicon Drift Detector (SDD) with a 125 to 140 eV FWHM @ $5.9 \mathrm{keV} \mathrm{Mn} \mathrm{K \alpha}$ line Energy Resolution (depends on peaking time and temperature); $1 \mathrm{keV}$ to $40 \mathrm{keV}$ detection range of energy; max rate of counts to $5.6 \times 10^{5} \mathrm{cps}$; software for acquiring and processing the XRF spectra.

Primary beam and detector axis form an angle of 0 and 40 degrees respectively with the perpendicular to the sample surface. Measurement parameters were as follows: tube voltage $35 \mathrm{kV}$; current $80 \mu \mathrm{A}$, acquisition time $100 \mathrm{~s}$; no filter was applied between the X-Ray tube and the sample; 
a

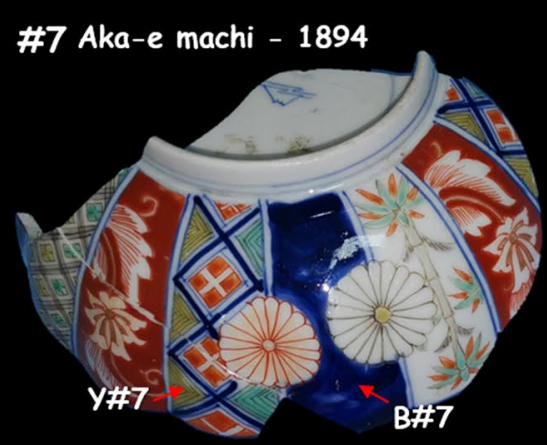

\section{\#9 Izumi yamakutiyabanshyo (1932-1945)}

\#8 Aka-e machi - 1868
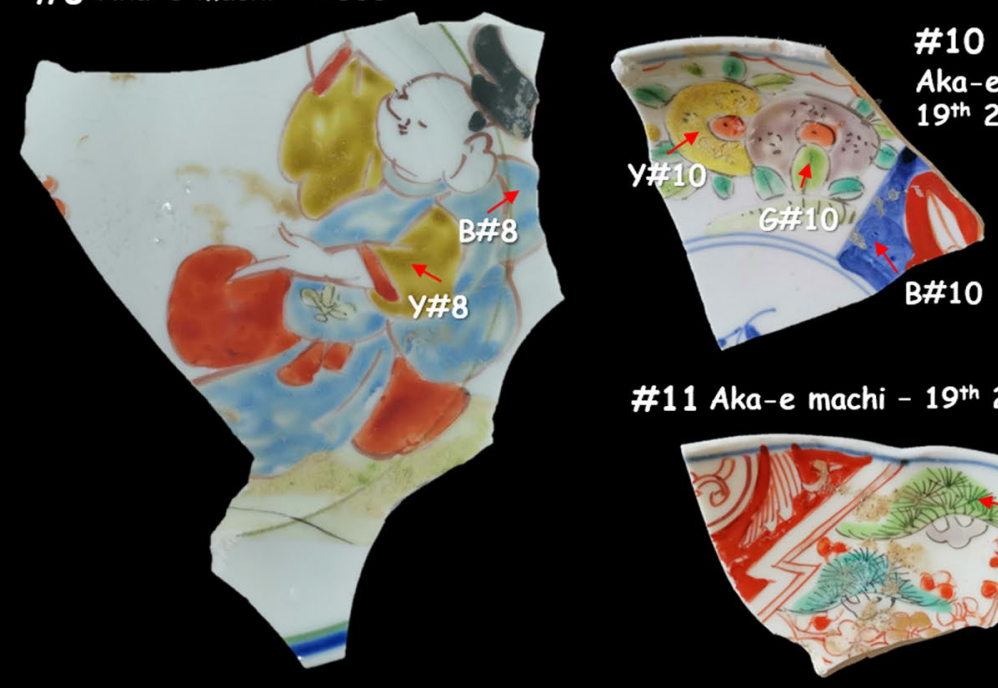

\#11 Aka-e machi - $19^{\text {th }} 2^{\text {nd }}$ half $c$.

b

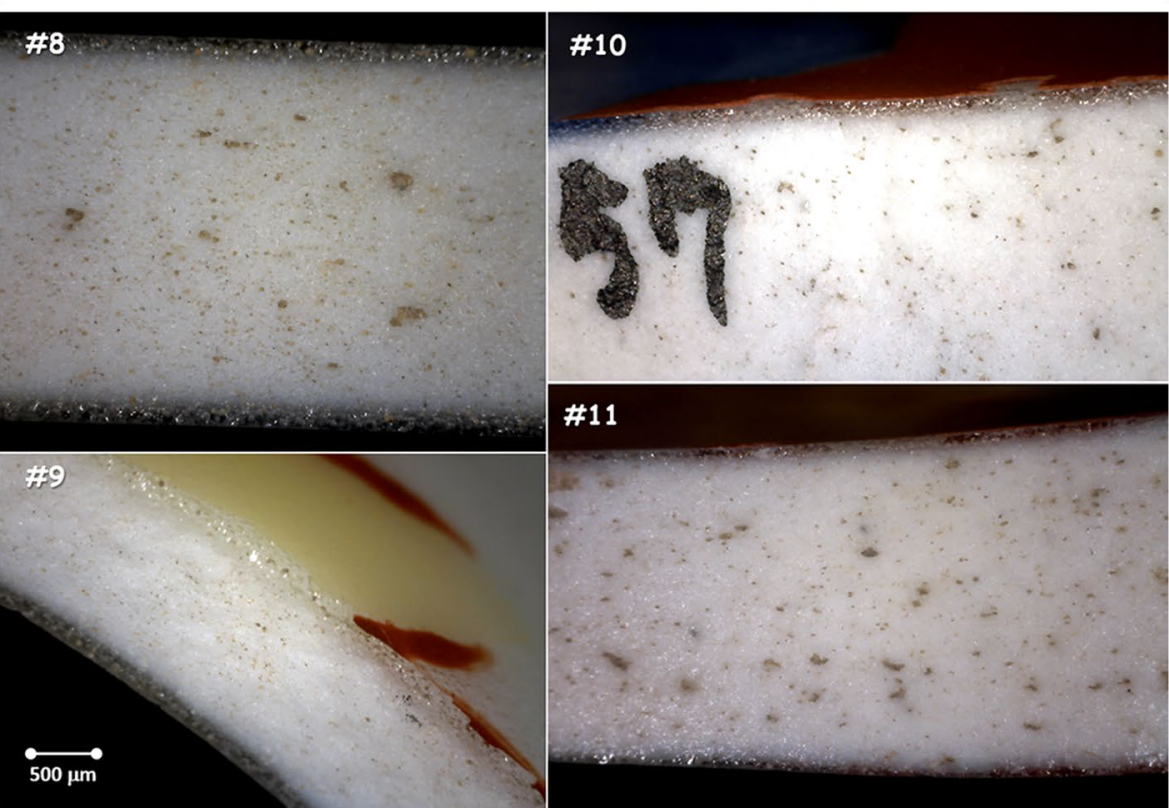

Fig. 1 a Analyzed shards with underglaze and overglaze decoration. Kiln sites, production date and XRF or Raman measurement areas are given (the dimensions are here reported: Shard \#7: $12 \times 9 \mathrm{~cm}^{2}$; \#8: $16 \times 13 \mathrm{~cm}^{2}$; \#9 diameter: $9.8 \mathrm{~cm}$; \#10: $\left.9.5 \times 8 \mathrm{~cm}^{2} ; \# 11: 7 \times 5 \mathrm{~cm}^{2}\right)$. b Fracture sections

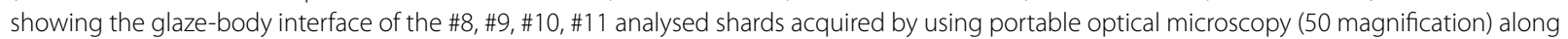
the fracture lines without any sampling 
distance between sample and detector around $1 \mathrm{~cm}$. The setup parameters were selected to have a good spectral signal and to optimize the signal to noise ratio (SNR). Measurement data were processed using the factory provided data reduction DPPMCA software, which enables the acquisition, display, and control for Amptek signal processors and allows the automatic peak recognition supported by manual peak selection and checking. The software further enables curve fitting based on chosen elements to ensure a match between the measured spectra and theoretically predicted spectra calculated from fundamental parameters (FP). Finally, XRF spectra have been graphically provided by Origin Pro 8.5.

\section{Raman spectroscopy}

The micro-Raman analysis was performed through a Renishaw InVia Raman Microscope (UK). The fragments were examined without any preparation. In order to make the fragment surface perfectly perpendicular to the laser path and to improve the focus, the shards were positioned on a clay base. Two exiting wavelengths were used: $532 \mathrm{~nm}$ and $633 \mathrm{~nm}$. The diffused light was recorded in a backscattered geometry using a $50 \times$ objective at long focal distance, in order to obtain a measurement spot of about 4 microns in diameter. Spectra were managed by Wire 2.0 software, associated to the Renishaw instrument.

\section{Results and discussion}

The overglaze enameled shards analyzed in this study are characterized by the presence of coloring agents of European origin. We will discuss the Raman and XRF data recorded on the different colored areas, yellow, blue, and green.

\section{Overglaze yellow enamels Raman analysis}

The Raman spectra detected on the nineteenth and twentieth century Japanese yellow enamels and on the seventeenth century mukozuke dish are reported in Fig. 2.

Naples yellow pyrochlore is a non-stoichiometric $\mathrm{A}_{2-\mathrm{x}} \mathrm{A}^{\prime} \mathrm{B}_{2-\mathrm{y}} \mathrm{B}_{\mathrm{y}}^{\prime} \mathrm{O}_{7^{-} \delta}$ phase built with two sub-lattices, one of (big) A cations $\left(\mathrm{A}=\mathrm{Pb}^{2+}\right.$ in the case of Naples yellow pigment), the second of (small, covalent bonded) cations $(\mathrm{B}=\mathrm{Sb}, \mathrm{Sn}, \mathrm{Fe}, \mathrm{Zn}, \mathrm{Si}, \mathrm{Zr} . .$.$) forming tetrahedral$ and octahedral entities sharing some oxygen atoms [23, 24]. B cations are easily oxidized/reduced and thus the formula and oxygen stoichiometry depend on the firing atmosphere. Due to the high mass of lead, the Raman signature show a characteristic strong peak arising from the $\mathrm{Pb}$ translational mode at low wavenumber, ranging from $\sim 125$ to $\sim 140 \mathrm{~cm}^{-1}$ as a function of the composition/structure [13-15, 17, 25]. Studies of Sn-O and Sb-O end members have allowed the identification of the $\mathrm{Sn}-\mathrm{O}$

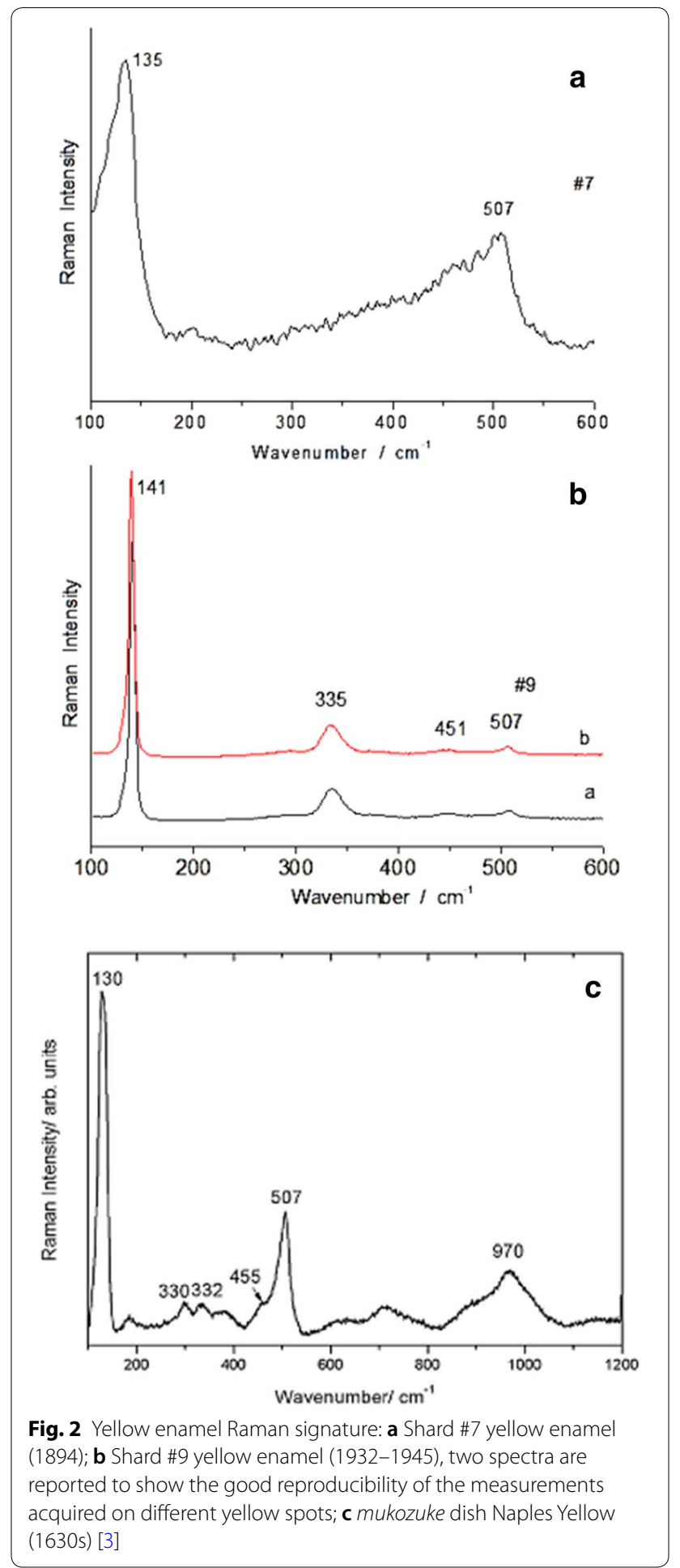

and $\mathrm{Sb}-\mathrm{O}$ stretching modes (stretching modes are strong in Raman spectroscopy) at ca. 450 and $505 \mathrm{~cm}^{-1}$ respectively [17]. Thus differentiation between Sn-rich and Sb-rich Naples Yellow is obvious from their Raman spectrum: Sb-rich pigment shows two strong peaks at ca. 130 
and $505 \mathrm{~cm}^{-1}$, while $\mathrm{Sn}$-rich pigment shows a spectrum with peaks at $\sim 130,325,450$ and $505 \mathrm{~cm}^{-1}$ [17].

As shown in Fig. 2, the spectra recorded on the yellow decorations of shards \#7, \#9, and the previously analysed seventeenth century mukozuke porcelain, all show a strong ca. 130-140-505 $\mathrm{cm}^{-1}$ doublet, characteristic of a Sb-rich Naples Yellow pyrochlore. However, the three yellow enamels feature different wavenumber positions of the strong $\mathrm{Pb}$ mode, namely 135, 141 and $130 \mathrm{~cm}^{-1}$, and all prove to be a shift higher than the uncertainty of the measure.

The lowest value detected on the mukozuke dish, $130 \mathrm{~cm}^{-1}$, corresponds to a firing temperature in the range of $900-1000^{\circ} \mathrm{C}$ according to Sakellariou et al. [16]. Such temperature value is consistent with the firing temperatures that characterize lead antimonate yellows in Renaissance Italy [13, 16, 18, 26-30].

\section{XRF analysis}

XRF spectra recorded on yellow colored areas show strong $\mathrm{Pb}$ peaks and medium $\mathrm{Si}$ peaks as expected for lead-based overglaze enamels.

The $\mathrm{Pb}-\mathrm{Sb}$ yellow detected on shard \#7 (Fig. 3a) and the $\mathrm{Pb}-\mathrm{Fe}-\mathrm{Sb}-(\mathrm{Zn})$ yellow detected on shard \#9 (Fig. 3b) both bear an enamel matrix consisting of the ternary system $\mathrm{Pb}-\mathrm{Si}-\mathrm{K}$. Such matrix composition, along with the presence of antimony, strongly points to the recipe reported by Takamatsu in 1878 [31]: Shiratama (PbO, $\mathrm{SiO}_{2}, \mathrm{~K}_{2} \mathrm{O}$ ) and Tojirome, an antimony-based compound, are listed as the main components to be used for yellow decoration "...nearly pure antimony... also called Toshirome...is used as a yellow enamel with Shiratama and other bodies, whereby oxides of antimony and lead are formed which give the yellow colour". This description confirms that the preparation of the antimony-based enamel differs from the European Renaissance recipe. The Japanese yellow color is not the specific compound obtained through calcination as the traditional European method employed for Naples Yellow required [16, 18], but it appears to be basically a by-product of the reaction between the mixed reagents. Comparison with the spectrum of the Italian Renaissance Naples Yellow (lead-antimonate yellow) detected on the famous mukozuke dish dated 1624-1644 (Fig. 3c) [3] clearly shows that the late Renaissance enamel consists instead of a $\mathrm{Pb}-\mathrm{Si}$ matrix with no significant amount of potassium: the yellow on the mukozuke dish perfectly matches the recipe for Giallo de' Vasari (Potters' yellow) published by Valerio Mariani in 1620 in the treatise Della Miniatura [13, 14].

The $\mathrm{Pb}-\mathrm{Cr}$ yellows detected on shards $\# 8$ and \#10 (Fig. $4 \mathrm{a}, \mathrm{b}$ ) prove to belong to the $\mathrm{Cr}$-based enamels developed in Europe in the early nineteenth century. The use of $\mathrm{Cr}$-based enamels for ceramic decoration was
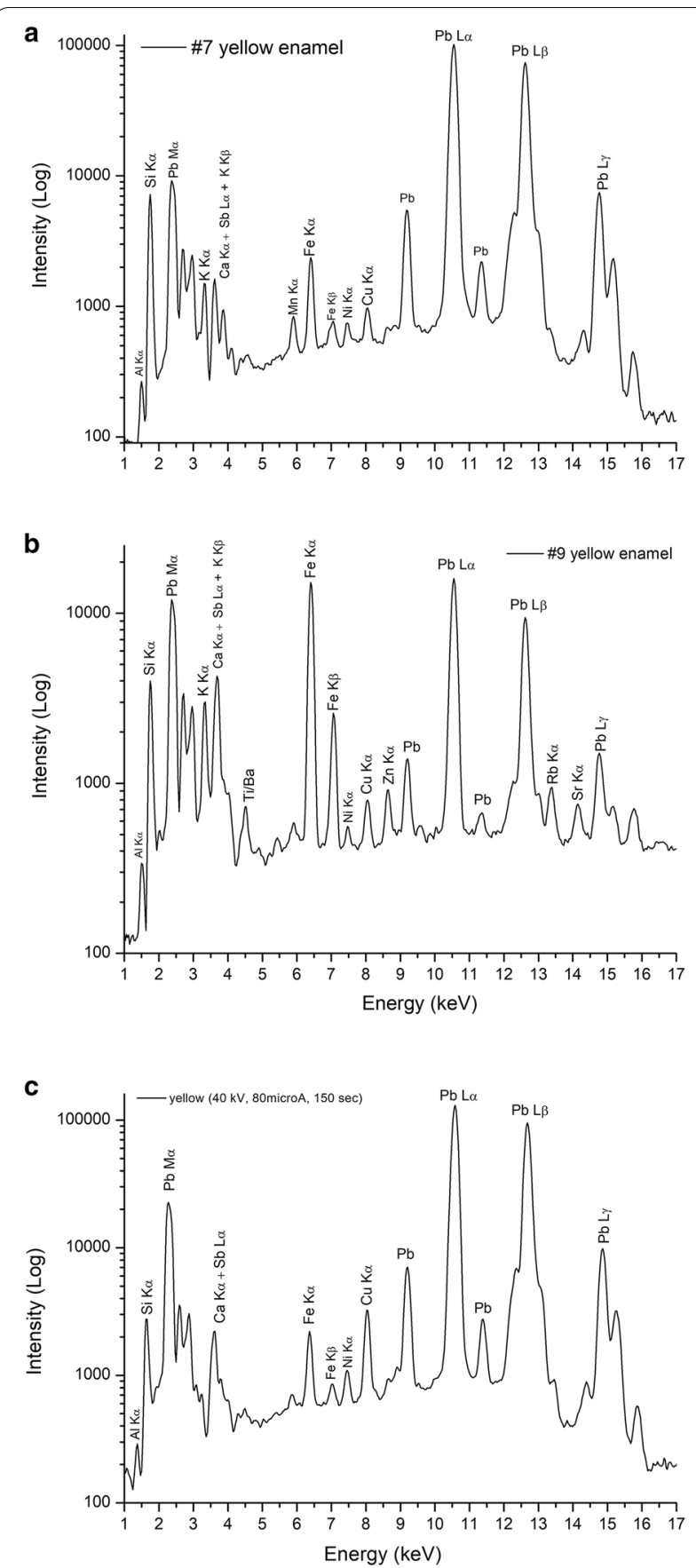

Fig. 3 Representative XRF spectra recorded on yellow coloured areas: a Shard \#7 Pb-Sb yellow (1894); b Shard \#9 Pb-Fe-Sb-Zn yellow (1932-1945); c previously analyzed mukozuke dish Pb-Sb Naples Yellow (1630s) [3]

emphasized by Vauquelin, the discoverer of the element chromium [32]. These new findings are consistent with the previous detection of a Cr-based yellow enamel on a porcelain cup produced in Arita in the second half of the nineteenth century [4] (Fig. 4c), thus confirming the 

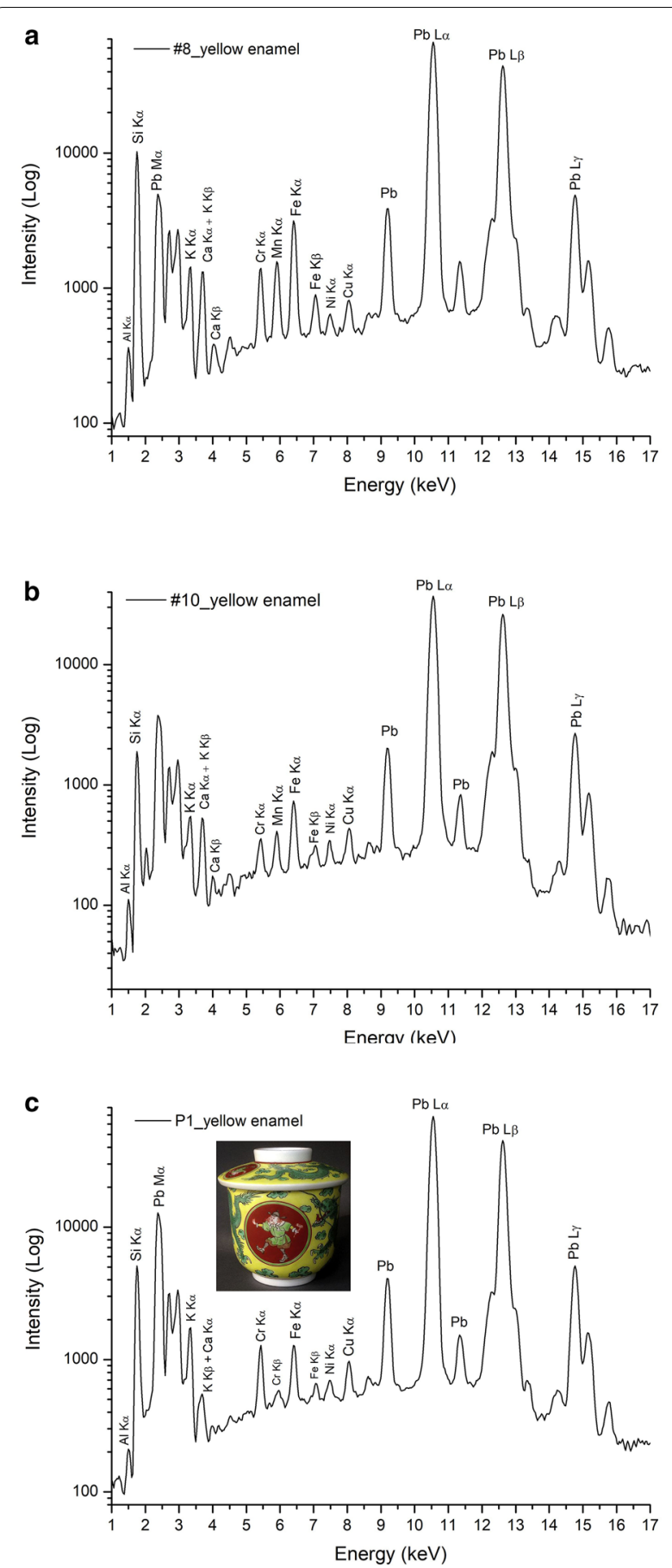

Fig. 4 Representative XRF spectra recorded on yellow area: a Shard \#8 Pb-Cr yellow (1868-1912); b Shard \#10 Pb-Cr yellow (1850-1900); c porcelain cup produced in Arita in the second half of the 19th century $\mathrm{Pb}-\mathrm{Cr}$ yellow 4

incorporation of such chromophore in the Japanese porcelain industry in the early-to-mid nineteenth century.

\section{Blue coloring agent and overglaze enamels}

The XRF spectrum of the underglaze blue pigment detected on shard \#7 shows a manganese to cobalt ratio $(\mathrm{Mn} / \mathrm{Co}<1)$ incompatible with the use of a natural and pure Asian cobalt ore [33, 34]. This demonstrates that the chromophore consists of a mixture of natural cobalt imported from China and a synthetic blue material developed in Europe (Fig. 5a). It is interesting to note here that the practice of mixing different grades of blue materials in Japan started in the mid-seventeenth-century when trade with Europe became the main drive of the porcelain industry in Arita: western taste demanded heavy decoration and Japanese potters needed to save up on material cost in order to improve profitability [4].

The XRF spectrum recorded on the overglaze blue decoration of shard \#8 (Fig. 5b) shows a chemical composition consistent with the European smalt-based enamel characterized by the elements $\mathrm{Ni}-\mathrm{Fe}-\mathrm{As}$ in association with Co. European sources of cobalt are vein of arsenates secondary deposits, while Asian cobalt sources are primary deposits rich in Fe and Mn [35]. The XRF spectrum recorded on shard \#9 shows instead the use of an overglaze blue enamel based on a compound of $\mathrm{Co}$ and $\mathrm{Zn}$ (Fig. 6a).

The results unquestionably prove that starting from the second half of nineteenth century and well into the twentieth century, Japanese potters gradually replaced most of the low-grade natural cobalt ores (rich in manganese and iron) imported from China and the smalt-based overglaze blue enamel imported from the Old Continent with Co-based synthetic pigments of European origin characterized by a higher coloring power and less sensitivity to firing atmosphere. This same type of blue material appears to have been consistently used until the present day as testified by the analysis carried out on a contemporary polychrome porcelain cup of high artistic value fired in Arita (Fig. 6b).

\section{Overglaze green enamels}

Visual inspection of the green colored shards herein analyzed strongly points to the intentional use of different compounds aimed at achieving various chromatic effects. Besides the expected use of copper ions dissolved in the glassy matrix for the traditional green color [7], a $\mathrm{Cu}-\mathrm{Cr}$-containing enamel was detected on shard \# 10 by XRF (Fig. 7a). Such instance is in perfect agreement with the recipe published in 1869 by Thomas Salter in Field's Chromatography or Treatise on Colours and Pigments as Used by Artists: the author lists a $\mathrm{Cu}-\mathrm{Cr}$ pigment that "... may be prepared by several methods".

Furthermore, the light-green enamel analyzed on shard \#11 (Fig. 7b) proves to originate from the mixture of $\mathrm{Sb}$ and $\mathrm{Cu}$. In particular the color is obtained by adding $\mathrm{Cu}$ 

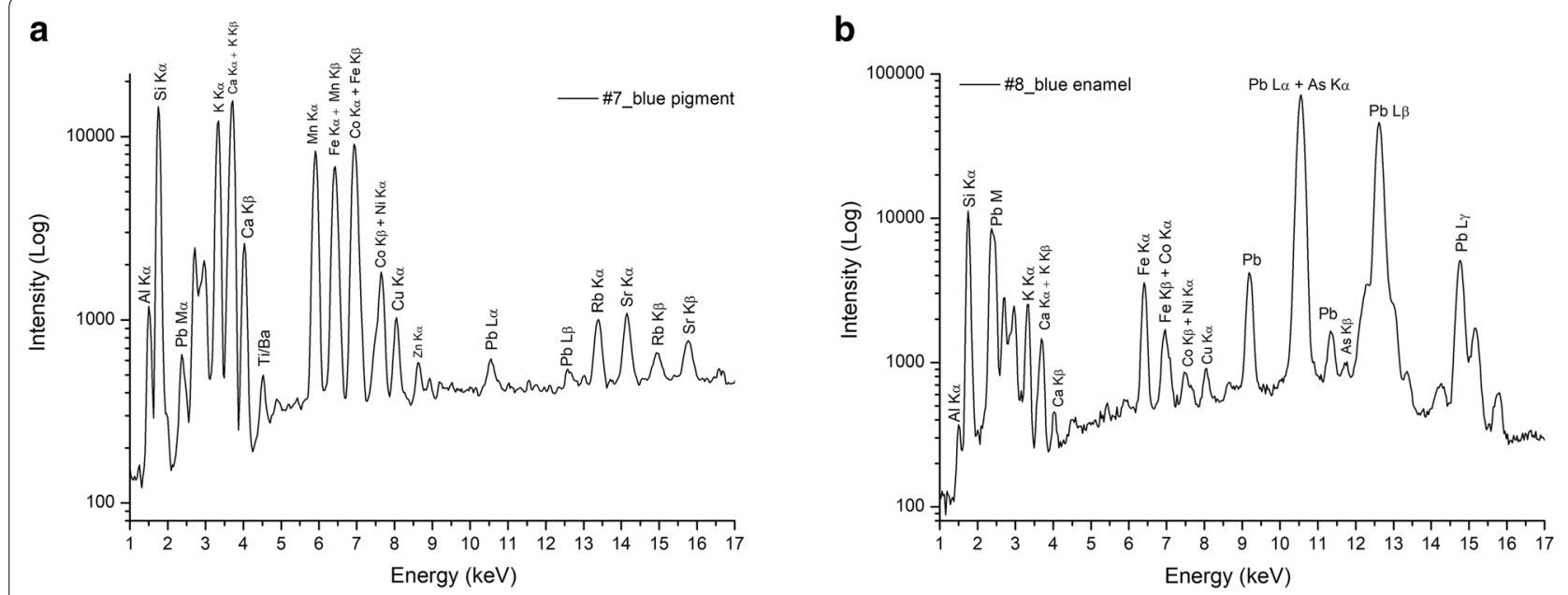

Fig. 5 Representative XRF spectra of recorded on blue areas: a Shard \#7, underglaze blue pigment (1894); b Shard \#8 (1868), overglaze $\mathrm{Pb}$-containing blue enamel
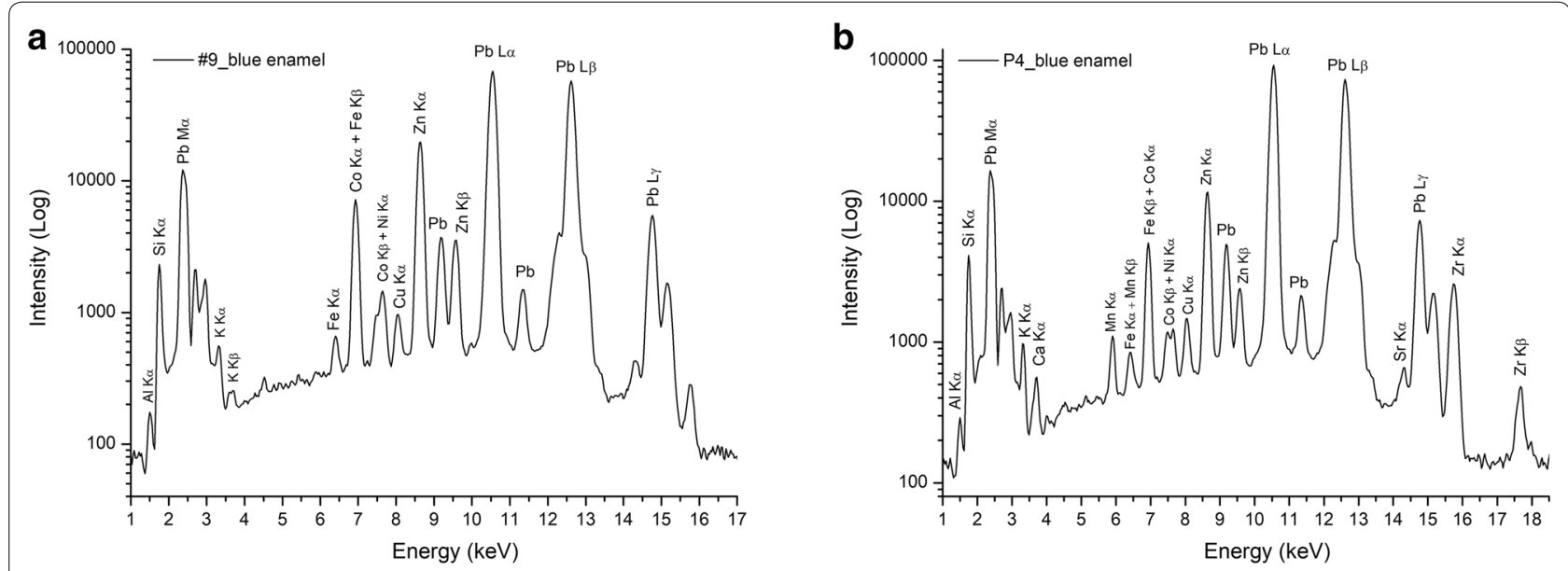

Fig. 6 Representative XRF spectra recorded on blue areas: a Shard \#9 (1932-1945), lead-based overglaze; b Contemporary overglaze lead based blue enamel

to the recipe for the $\mathrm{Pb}-\mathrm{Sb}$ yellow detected on shard \#7 (Fig. 3a). Noteworthy is to mention here the Renaissance recipe by Cipriano Piccolpasso, who listed in his " $\mathrm{Li}$ Tre Libri dell'Arte del Vasaio" (The Three Books of the Potter's Art) in the mid-sixteenth century, a "mixed" green pigment consisting of a mixture of $\mathrm{Cu}, \mathrm{Pb}$ and lead antimonate yellow [36]. Such record well traces the Italian origin of the later-developed northern European recipes that spread in the Far East in the nineteenth century as here demonstrated.
Naples yellow pigment: a tracer of Europe-Japan technological exchanges Preparation procedures

As previously presented, the $\mathrm{Pb}-\mathrm{Sb}$ yellow enamel detected on shard \#7 (Fig. 3a) and the $\mathrm{Pb}-\mathrm{Fe}-\mathrm{Sb}-(\mathrm{Zn})$ yellow detected on shard \#9 (Fig. 3b) both bear a $\mathrm{Pb}-$ $\mathrm{Si}-\mathrm{K}$ matrix. This enamel composition is perfectly consistent with the recipe reported by Takamatsu in 1878 [31], therefore the preparation of the $\mathrm{Pb}-\mathrm{Sb}$ and $\mathrm{Pb}-\mathrm{Fe}-$ $\mathrm{Sb}-(\mathrm{Zn})$ compounds clearly differs from the calcination process required for the production of the European Renaissance Naples yellow. Moreover, no K was detected on the mukozuke dish (Fig. 3c) as expected for a lead antimonate compound prepared according to Valerio 

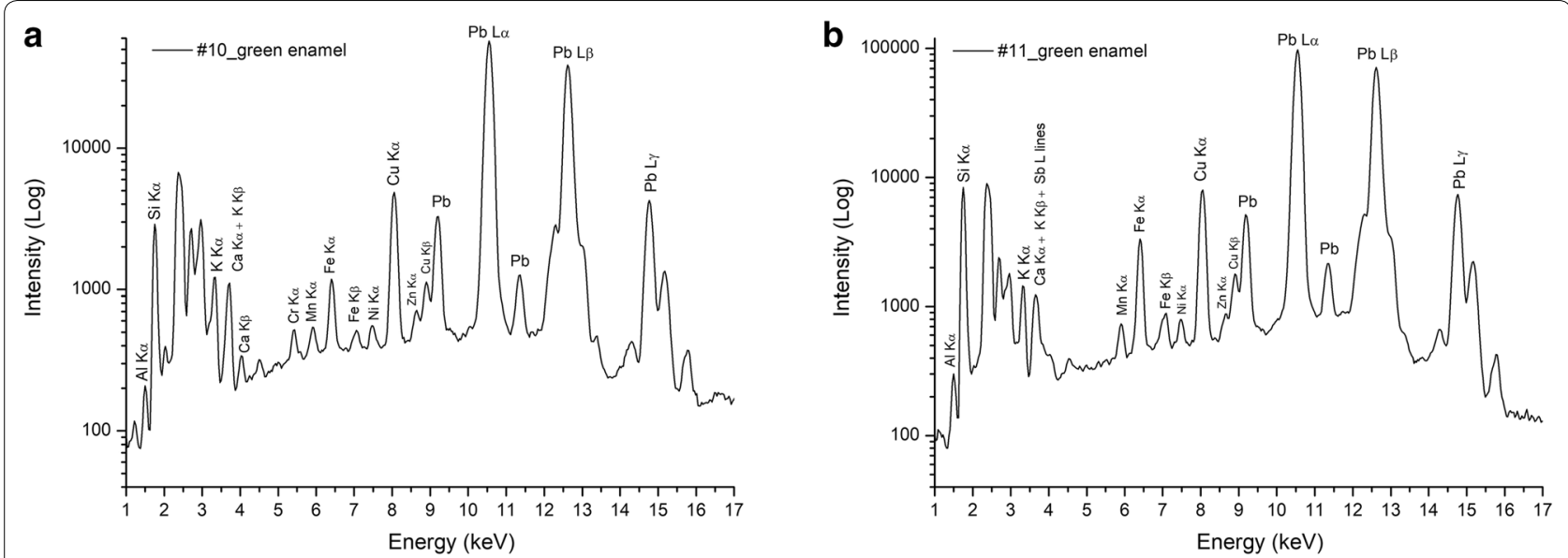

Fig. 7 Representative XRF spectra recorded on green area: a Shard \#10 (19th 2nd half c.); b Shard \#11 (19th 2nd half c.)

Mariani's recipe for Giallo de' Vasari (Potters' yellow) published in the treatise Della Miniatura (1620) [18]. The implication is clear: the composition of the Japanese yellow enamels differ dramatically from the common Italian Renaissance recipes. The Renaissance yellow bears the fluxing agent $\mathrm{NaCl}$, while the nineteenth-century Japanese yellows show the employment of a K-based flux, thus proving to belong to the group of contemporary antimony-based yellows developed in northern Europe $[26,37]$ on the basis of the original Italian process published by Passeri in 1758. The French scientist Fougeroux de Bondaroy (1769) was the first to have modified the process by adding potassium alum, and the other northern European recipes followed suit [26, 37].

The results perfectly fit into the trade picture of the nineteenth century, when new materials were being imported into Japan from northern Europe by the Dutch $[4,31,38]$. As a consequence of the isolation policy enforced by Tokugawa Shogunate, European materials available for porcelain production and paintings differed over the centuries. The mukozuke dish was decorated with a Renaissance yellow enamel of Italian origin imported by the Jesuits in the early 1600 s, while the nineteen-century porcelains were enameled with a yellow color based instead on the recipes developed in northern Europe in the nineteenth century.

Yet the Japanese created their own path and changed the actual production process of the coloring agent. European recipes required the calcination of a mixture of antimony oxide and lead oxide to achieve a stable Naples Yellow compound to be embedded in the $\mathrm{NaCl}$ fluxed matrix $[16,18,39]$, as consistently detected on the mukozuke dish. The Japanese method involved instead the use of different bodies providing a $\mathrm{Pb}-\mathrm{Si}-\mathrm{K}$ matrix to which an antimony compound, pure antimony from Iyo province [31], was then added. No previous calcination was carried out, thus leading to different enamel characteristics in terms of formed phases and reagents stoichiometry. Raman spectra (Fig. 2) provide further crucial information as to the firing temperatures of the antimony-based compounds, thus enabling the identification of their geographical area of origin and, along with XRF compositional data, their period of production.

\section{The Raman signature of the pyrochlore solid solution}

In order to fully understand this point, we have to consider that lead antimonate belongs to the family of compounds with the ideal pyrochlore structure having the general formula $\mathrm{A}_{2} \mathrm{~B}_{2} \mathrm{O}_{6} \mathrm{O}^{\prime}[13,16,27,28,40,41]$. B-O bonds are crucial to the cohesion of the crystal and a regular $\mathrm{BO}_{6}$ polyhedron entails a more-distorted $\mathrm{AO}_{8}$ polyhedron and vice versa $[40,41]$. The $(\mathrm{B}-\mathrm{O})$ force constants are six to eight times stronger than those of $\mathrm{f}(\mathrm{A}-\mathrm{O})$ and $\mathrm{f}\left(\mathrm{A}-\mathrm{O}^{\prime}\right)$ [40, 41]. Firing temperature, stoichiometric ratio, and small distortions of the pyrochlore structure strongly affect the $\mathrm{Pb}$ mode of the $\mathrm{A}_{2} \mathrm{O}^{\prime}$ lattice. Yet even a significant perturbation of the $\mathrm{A}_{4} \mathrm{O}^{\prime}$ network has a weak influence on the $\mathrm{BO}_{6}$ network and overall rigidity of the structure $[40,41]$. Therefore, from a vibrational standpoint, the two networks appear, on first approach, to be energetically independent [41]. The implication is clear: the firing temperature for enamel decoration affects the Raman wavenumber of the $\mathrm{Pb}$ mode to such a greater extent than the compositional base of the matrices in which the chromophore is embedded or the respective molar ratios. The lower the value of the diagnostic-peak wavenumber, the more stable the structure of the pigment owing to the increasing firing temperature [16]. It has been firmly demonstrated that as the firing temperature increases, the peak shifts to lower wavenumbers: 
$134 \mathrm{~cm}^{-1}$ at $800{ }^{\circ} \mathrm{C}, 130 \mathrm{~cm}^{-1}$ at $950{ }^{\circ} \mathrm{C}$, and $124 \mathrm{~cm}^{-1}$ at $1100{ }^{\circ} \mathrm{C}$ [16]. The peak at $130 \mathrm{~cm}^{-1}$ observed on the Naples yellow used to decorate the mukozuke dish (Fig. 2c) matches the reported data perfectly, confirming an Italian Renaissance lead antimonate yellow fired at $900-1000{ }^{\circ} \mathrm{C}$ ('Feu de moufle'). A firing temperature in the range of $900-1000{ }^{\circ} \mathrm{C}$ is incompatible with either the ceramic technology at Jingdezhen where overglaze enamels were fired at $700-800{ }^{\circ} \mathrm{C}[42,43]$ or a Chinese enamelon-metal technology with enamels fired at $600-700{ }^{\circ} \mathrm{C}$ $[44,45]$. The latter, in particular, employs additional fluxing agents such as $\mathrm{CaF}_{2}$ or even $\mathrm{Bi}_{2} \mathrm{O}_{3}$ [44] that lower the processing temperature, thus relying on a thermal-treatment duration which clearly differs between China and Europe in terms of kiln technology and heating rate.

The values of the diagnostic-peak wavenumbers observed on Chinese wares of any media, be it porcelain or metal, from any period and recipe, that were decorated with a lead antimonate yellow enamel $[42,44]$ fall within the range $136-142 \mathrm{~cm}^{-1}[42,44]$. They therefore fit into the firing-temperature range associated with both technologies in China, namely $600-800{ }^{\circ} \mathrm{C}$ [42-45]. As a consequence, a Chinese origin and firing of the yellow enamel is to be ruled out on the basis of such experimental evidences.

The strong peaks at $135 \mathrm{~cm}^{-1}$ and $141 \mathrm{~cm}^{-1}$ detected on the Japanese nineteenth-century $\mathrm{Pb}-\mathrm{Sb}$ and $\mathrm{Pb}-\mathrm{Fe}-$ $\mathrm{Sb}-(\mathrm{Zn})$ yellows (Fig. 2a,b), unequivocally point to a firing temperature in the range of $700-800{ }^{\circ} \mathrm{C}[16,42]$ as confirmed by kiln practice for the period in Arita.

To conclude, based on the evidence discussed so far, the implication is very clear: the firing temperatures and chemical compositions of the Chinese Naples Yellows [42-46], be it on metal or ceramic, and the Japanese nineteenth century Naples Yellow, all differ dramatically from the Naples yellow of European origin that was detected on the mukozuke dish fired in the late Renaissance period (1630s). The latter shows a Raman signature consistent with the firing temperature of $950{ }^{\circ} \mathrm{C}$ as identified identified by Impey for the firing of Arita wares in the early Edo period $[47,48]$, as well as the firing temperature needed in Renaissance Italy to obtain a brighter and richer antimony-based yellow color [16]. The results point to a firing process the mukozuke dish underwent in western Arita, most likely at the Yanbeta kiln, under the supervision of European missionaries in the 1630s, before the final expulsion of all missionaries in 1639.

\section{Historical recipes and scientific evidence: the connections Provenance and use of antimony}

Documentary evidence and recent studies confirm that antimony was imported into Japan during the seventeenth century $[4,31,38,48,49]$. In particular, a Dutch record for the year 1690 mentions the import of antimony into Japan as specifically needed for the decoration of porcelain wares $[48,49]$. This instance is a highly significant one as Dutch traders knew the pigments being exported very well, considering that those same pigments, that is, lead-antimony and lead-tin yellows, started being imported into China from Europe around the same period, after the glass workshop had been established in the Palace in 1695 as ordered by the Kangxi Emperor to Jesuit missionaries [8, 42, 46, 50, 51]. In fact, Teodorico Pedrini (a Lazarist), who arrived in China with the painter Matteo Ripa to work at the court of the Emperor Kangxi, petitioned Rome in 1711 for the supply of antimony (antimono non preparato) and enamels (smalti) needed for the production of new colors at the imperial workshop [8]. The missionaries were focusing on the preparation of new enamels, such as lead-tin yellow, lead-antimony yellow, arsenic-white and pink, that would enrich the Ming ceramic palette based on the traditional transition metals that Jingdezhen potters had been using for porcelain decoration until the Qing dynasty $[8,42$, $46,50,51]$. Moreover, the Dutch record mentioning antimony in 1690 triggered the suggestion [48] that antimony may have been the coloring agent used by Kakiemon in the late seventeenth century to produce the classic wares that took Europe by storm.

From a compositional standpoint, the chemical elements detected on the lead-iron-antimony yellow on shard \#9 (Fig. 3b) offer, for the first time, crucial information regarding the actual recipe that formed the basis of Japanese porcelain decoration in the nineteenth and twentieth century. The presence of $\mathrm{Fe}, \mathrm{K}, \mathrm{Zn}, \mathrm{Sb}$ and $\mathrm{Pb}$ strongly points to the recipe developed by LouisAlphonse Salvetat at Sèvres in the mid-nineteen century. A Fe-based enamel characterized by the addition of $\mathrm{Sb}$ and $\mathrm{Zn}$ is listed in Leçons de Céramique published by Salvetat in 1857: "Fondant 880, Fleurs de zinc 35, Oxide de fer hydraté jaune 70, Antimoine diaphorétique 15".

Noteworthy is that the French recipe well matches the chemical composition of the yellow enamel detected on shard \#9: the Arita enamel is a traditional Fe-based yellow with the addition of $\mathrm{Sb}$, and $\mathrm{Zn}$ in a $\mathrm{Pb}-\mathrm{Si}-\mathrm{K}$ based matrix (Shiratama and other bodies as described by Takamatsu).

The Raman spectrum (Fig. 2b) has confirmed the nature of the compound acting as coloring agent, and has also shown the different stoichiometry of the reagents and the different firing temperature as compared to European kiln practice.

The significant presence of $\mathrm{Zn}$ is clearly the result of the influence of Salvetat's method. Its addition, as also described by Theodore Deck in La Faïence published in 1887, helped obtaining different shades of an opaque 
yellow in combination with $\mathrm{Sb}$ and $\mathrm{Pb}$. Salvetat further explains in Leçons de Céramique how the use of $\mathrm{Zn}$ helps achieving a brighter yellow. Japanese potters appear to have followed such instructions to obtain a bright and opaque yellow for porcelain decoration.

This new enamel also reveals a very interesting transition from the Japanese traditional Fe-based yellow to the new $\mathrm{Sb}-\mathrm{Zn}$-containing European recipe. A clear instance of this change is represented by the Nabseshima shard (1690-1730) (Fig. 8a, b) and the Ko-imari Cup (17701790) (Fig. 8c, d) as compared to the shards analyzed in this work. The translucent $\mathrm{Pb}-\mathrm{Fe}$-based yellow enamel employed on the highly traditional Nabeshima shard and Ko-Imari cup appears to have been consistently used from the mid-seventieth century, after the Jesuits had all been expelled from Japan, and throughout the eighteenth century. Japanese potters' practice of yellow enamelling with the translucent iron-based color in the eighteenth century is also reported in the book of recipes attributed to Johann Gregorius Höroldt (director of the Meissen manufacture) and dated to 24 December 1731: the "Yellow in the Japanese manner" is listed as consisting of iron compounds, contrary to the opaque Meissen yellow enamel based on lead antimonate [52].

Basically, Japanese potters ended up modifying their traditional translucent Fe-based recipe with minor additions of $\mathrm{Sb}$ and $\mathrm{Zn}$ to make it brighter and opaque. It appears very clear now how the transition must have been gradual and possibly smooth in terms of technological innovation as with other forms of applied arts. The same kind of approach emerges from ukiyo-e prints, where the incorporation of new synthetic colors of European origin proved gradual, selective, and coexisted with Japanese traditional practice [53].

The technological implications are very significant: the Renaissance opaque yellow enamel was based on a completely new and unknown technology that required Jesuit supervision in the first phase of enamel development in Japan in the 1630s, while the nineteen-century enamels were obtained by modifying the European methods on the basis of the Japanese established local tradition. The Japanese way developed by adapting European recipes to Japanese practice. It appears pretty clear how such approach led to the modification of the European recipes: the lead-antimonate yellow became the result of a mixture of compounds with no previous preparation by calcination; and the innovative incorporation of limited amounts of antimony and zinc into the traditional translucent Fe-based yellow helped making it brighter and opaque.

More details on the effect of the use of zinc in yellow enamels for porcelain decoration is revealed by Alexandre Brongniart in the treatise Colouring and Decoration of Ceramic Ware, published in 1898, where the author says "Oxide of zinc enters into the composition of greens, yellows, yellow-browns and blues...Oxide of zinc...develops qualities necessary for the beauty of certain colours". The use of zinc as an opacifier belongs to the European tradition as also testified by Salvetat in Leçons de Céramique.

\section{European materials for painting and ceramics}

The continued but very limited availability and circulation of European lead-based yellow chromophores in Japan is further clarified by the surviving early-seventieth-century painting depicting The Madonna with the Infant Jesus and her Fifteen Mysteries: the pigment leadtin yellow, unknown in Japan, was detected on the central inscription in Latin characters (romaji) "LOWADO SEIA O SANCTISSO SACRAMETO" [5]. This specific pigment belongs to the same family of Naples Yellow, the lead-antimonate enamel detected on the famous mukozuke dish fired in the Kan'ei period (1624-1644).

Noteworthy is to mention here that along with imported pigments and Japanese traditional coloring agents, flaxseed oil, a vegetable drying oil of European origin, unknown in Japan, not only was detected on the painting The Madonna with the Infant Jesus and her Fifteen Mysteries, but also on the western style screen Map of the World and Famous Cities (early seventeenth century), as the binding medium $[5,54]$. This crucial instance has led Oka to emphasize the influence of Western technology on painting production, and to identify the Jesuit Seminario as the source of the imported materials [54].

Such unrecorded use of Western materials is perfectly consistent with a period of strict enforcement of antiChristian edicts by the Tokugawa Shogunate [3, 12], with no chance for any written records mentioning any direct interaction with the missionaries to survive. Unfortunately, the yellow color on the screen Map of the World and Famous Cities was not analyzed.

\section{Porcelain and paintings: one coloring agent for both productions}

Additional important confirmation comes from the Yanbeta shard previously studied (Fig. 9) [4]: the composition of the green enamel analyzed on the shard perfectly matches the green pigment detected on the early-seventieth-century screen Western Kings on horseback [55]. In terms of technological implications, an early use of a $\mathrm{Cu}-$ As-Zn based green pigment has been clearly detected on the works by the sixteenth-century Italian painter Stefano Sparano [56]. Once again, the practice of using the same materials for paintings and ceramics is of European origin and does not belong to Japanese tradition. 


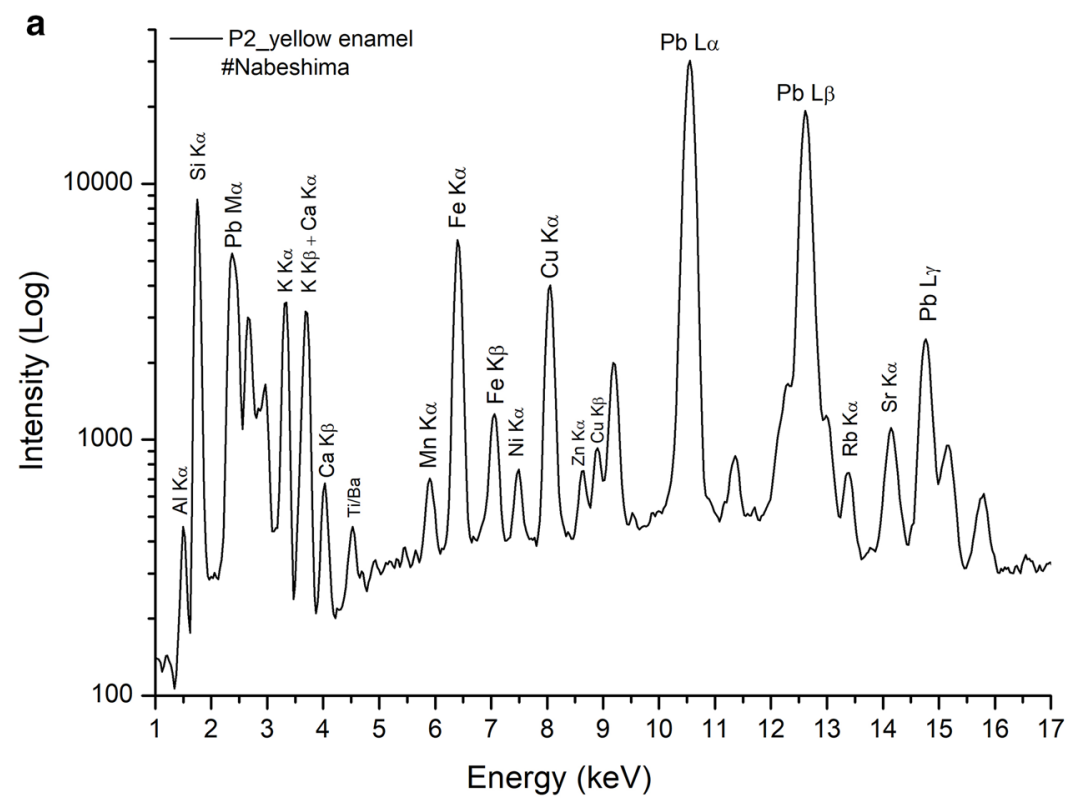

b

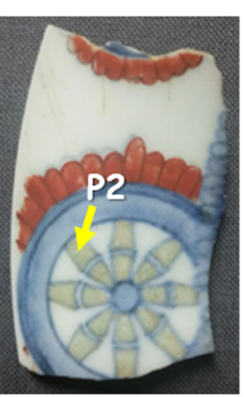

C

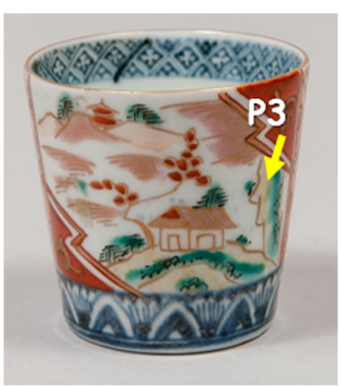

d

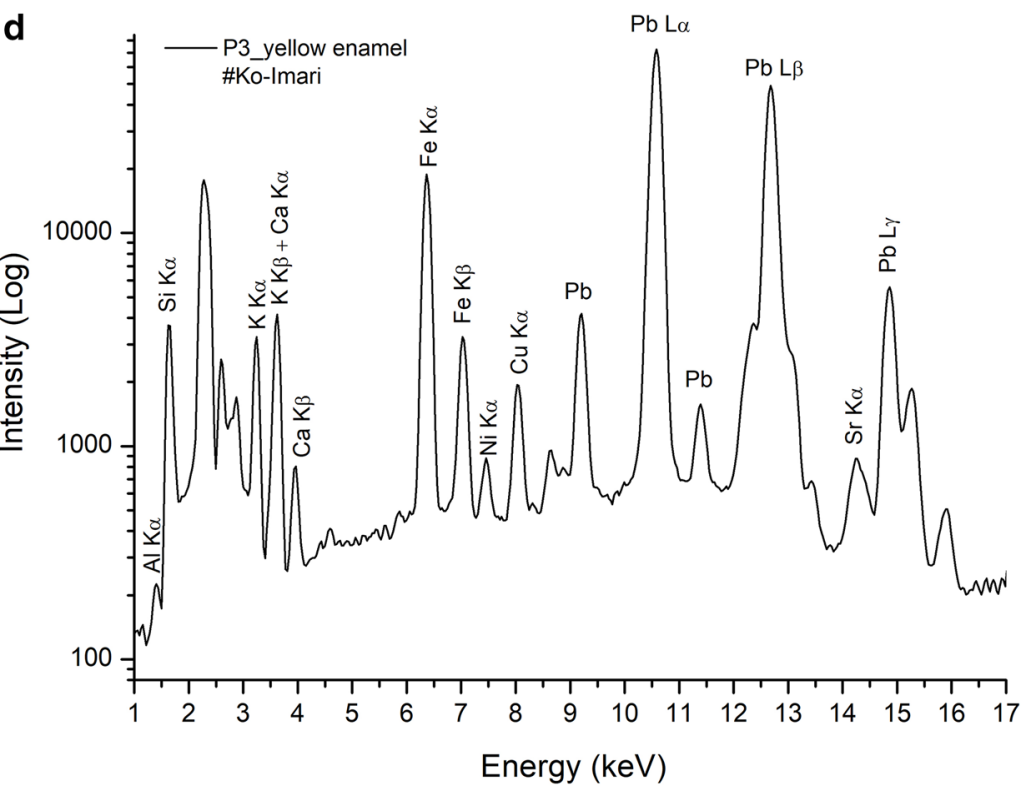

Fig. 8 a, b Nabeshima Shard (1690-1730) and Pb-Fe yellow enamel XRF spectrum; c, d Ko-Imari cup (1770-1790) and Pb-Fe yellow enamel XRF spectrum 


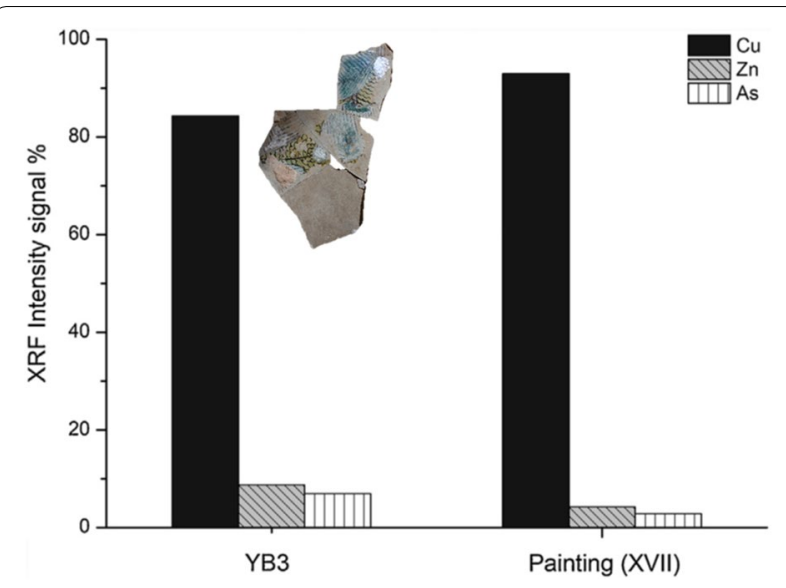

Fig. 9 Schematic of XRF signal of $\mathrm{Cu}, \mathrm{Zn}$ and As elements recorded on shard \# YB3 in a previous work [4]

\section{Persecutions and closure of the country}

European technology unknown to the Japanese was still available during the fierce persecutions that started in 1614 , but on a very limited basis. Therefore, the overall analytical evidence confirms that the imported materials influenced color decoration on paintings and ceramics until the final expulsion of all Christians in 1639. The sakoku (closed country) policy established by the Tokugawa Shogunate led to the strict control of anything that entered the country, and trade with Europe ended up being monopolized by the Dutch and the Chinese in Dejima, thus ending the phase of spontaneous westernization of the applied arts that had started in the mid-16th century thorough the effort of Jesuits missionaries.

\section{Blue coloring agents \\ Smalt: provenance and use}

Of particular interest is also the case of the overglaze blue enamel, the glass rich in potassium and colored by cobalt oxide, used in Europe since the fourteenth century for paintings and ceramics alike [57-60]. This blue pigment, also named smalt (saffre in French, smalto in Italian), has been detected on a hand-colored Japanese Buddhist print dated to the late 16th century [61], and on ukiyo-e paintings from the seventeenth to the late eighteenth century [38]. Recent systematic studies have demonstrated that smalt had initially been imported into Japan by the Jesuits for porcelain decoration in the late Kan'ei period (1624-1644), thus resolving the long-standing issue of the origin of the material $[4,62]$. Afterwards the Dutch monopolized the trade [38]. From the Kanbun era (16611673) the imported material was also employed on $u$ kiyo$e$ paintings [38]. Noteworthy is that there are no earlier examples of the use of smalt in the Asian paper or silk painting tradition [38], so Japan appears to have been the first country where the material started to be used under the supervision of Jesuit missionaries in the late sixteenth century.

This pioneer use of imported European materials proves perfectly consistent with the detection of leadantimonate yellow on the rare mukozuke dish (Fig. 2c, 3c), of lead-tin yellow on the painting The Madonna with the Infant Jesus and her Fifteen Mysteries, and of flaxseed oil on both The Madonna with the Infant Jesus and her Fifteen Mysteries and the western style screen Map of the World and Famous Cities. No wonder we find smalt on ukiyo-e works from the latter half of the seventieeth century: the supply of the material, as for the case of porcelain production [4], had stabilized at the time by means of the trade with the Dutch, who, to cope with the high demand, established a production facility in Holland [4, 38]. The pigment innovation of the late 16th century, as testified by the hand-colored Buddhist print [61], kept showing strong roots in the artists' creative approach. The detection of smalt on ukiyo-e paintings is very significant as ukiyo-e represented a new form of art that shaped popular culture during the Tokugawa Shogunate. Once again, as for the craze for anything European (Namban) that took Japan by storm in the Momoyama period (1568-1603), European innovations kept inspiring new experimentation that shaped the artistic forms of the whole Edo period (1603-1868).

Paintings and enameled porcelains were expensive commodities; therefore it makes perfect sense to have found the imported materials on works reserved for the wealthy. Significant instances of the use of smalt by Japanese masters come from the seventieth-century painting Flowers and Rocks by Ogata Korin (16551716) and the late-eighteenth-century Moonlight Revelry at Sagami Dozo by Kitagawa Utamaro [62].

In terms of pigment origin, full confirmation comes from the blue color analyzed on a Japanese votive painting dated 1682 [63]: the chemical composition of the pigment is $\mathrm{Co}-\mathrm{Ni}-\mathrm{Fe}-\mathrm{As}$, which, as expected, perfectly matches the composition of the European smalt-based enamel imported into Japan by the Jesuits in the late 1630s for overglaze blue decoration of porcelain wares [4]. It is worth noting here that the practice of using the same coloring agents for paintings and ceramics belongs to the European technological tradition. Japan therefore established itself as the first country to have incorporated European Renaissance technology into traditional Far Eastern applied arts.

Smalt, as for the case of Naples Yellow, lead-tin yellow and arsenic-opacified white, will acquire a central role in the new opaque enamel palette developed at 
Jingdezhen (China) from 1720s for the decoration of imperial wares $[7,8,42,64,65]$.

\section{Foreign coloring agents in the late Edo period (eighteenth and nineteenth centuries)}

Ukiyo-e paintings were gradually replaced by woodblock prints, an inexpensive mass produced form of art. Publishers needed to switch to less expensive and ready-touse materials in order for the prints to be enjoyed by the public at large: Prussian Blue, a synthetic pigment developed in the Old Continent in the early eighteenth century [66], started to replace smalt and coexist with native natural pigments from the early nineteenth century [67], as testified by masterpieces such as Doshoku Sai-e by the painter Ito Jakuchu (1716-1800) [68]. It is interesting to note here that smalt and Prussian Blue have been identified as being part of the Kaishunsai paints, the pigments collected by the Nabeshima family in the early nineteenth century and stored in Takeo city, Saga prefecture [69]. Takeo city is located in the vicinity of Arita, where the production of blue-decorated porcelains was recently discovered to have developed in the late $1630 \mathrm{~s}$ on the basis of a smalt-based enamel imported by the Jesuits [4]. The Nabeshima family controlled porcelain production in Arita, and the clan's crucial role became evident on the occasion of the organization and unification of the kilns that occurred in 1637 [70]. Such change was needed to exploit the full potential of the porcelain trade. So the presence of the pigments in the collection further testifies to the influence of European technology on art production in Japan throughout the Edo period.

\section{Comparison with China: smalt and European chromophores}

European technological influence on Chinese arts followed the exact same path established in Japan one century earlier. The Chinese, after the first technological exchange with the Jesuits in 1695 [7], started incorporating new imported materials into their artistic practice: smalt, lead-tin yellow, lead-antimonate yellow, Pb-SbSn yellow, arsenic white, Prussian Blue and new artificial pigments saw an extensive use in ceramics and paintings throughout the Qing dynasty and up to the present day $[42,64,65,71]$. Contrary to the case of Japan, Jesuit missionaries enjoyed imperial patronage in China and were free to exert their influence on the production of polychrome wares at Jingdezhen in the late seventeenth and early eighteenth century. In Japan the Jesuits were forced to hide when the young porcelain industry in Arita started developing the first overglaze enamels. Therefore the same gradual modification and incorporation of European recipes as identified in eighteenth-century China and late-nineteenth-century Arita, would have been impossible in the early seventeenth century when the fierce persecutions culminated in the final expulsion from Japan of all missionaries in 1639.

The two painting and ceramic traditions, Japanese and Chinese, however, differed for the extensive use of smalt that characterized the former and that almost completely lacked in the latter [7, 47, 72-75].

\section{European recipes for the global market: production innovations in the porcelain industry of Arita}

Domestic consumption of porcelain in Japan had spread by the late eighteenth century [76], yet the porcelain industry started to face a deep decline due to the reduced trade with Europe, kiln destructions by fire [76], and the fierce competition by the mass-produced Chinese copies of Imari wares that had flooded the European market in the eighteenth century $[73,74]$. Chinese traders were capable of taking full advantage of any business opportunity arising in the Far East. In this highly competitive environment, kiln owners in Arita needed to devise new strategies to make the whole process less expensive and meet domestic and western taste. The development of new colors involved the use of synthetic pigments made in Europe: the present results show how such decision became a dominant factor in enamel production. A clear shift to the newly-developed and cheaper materials took place in the nineteenth century, after a predominance of the traditional coloring agents in the seventeenth and eighteenth centuries (transition metals), yet with the continued import of the smalt-based blue enamel form the Old Continent.

In particular Takamatsu describes the imported blue material from Europe in 1878 [31] by saying: "No certain information of the manufacture of this substance has been obtained at present. It is said that it may be prepared by fusing crude oxide of cobalt with a mixture of clay and alkalies, so as to form a kind of blue glass, or smalt. At present foreign smalt is largely used, being sold at a cheaper rate".

Takamatsu therefore records that the blue pigment, known in Japan as Hanakonjo, was being imported as a ready-to-use material, thus confirming that Japanese painters and potters had not yet established a local production and kept relying on the European supply until the early twentieth century [31, 77], as also demonstrated in this work. The continued use of imported smalt remained unchanged since the late 16th century, as testified by the Japanese votive pictures and ukiyo-e paintings, up until the twentieth century [77]. Our results have also shown that the blue pigment employed in Arita from the late nineteenth century consisted of the newly developed Co-based synthetic material of European origin that gradually replaced smalt for overglaze decoration, 


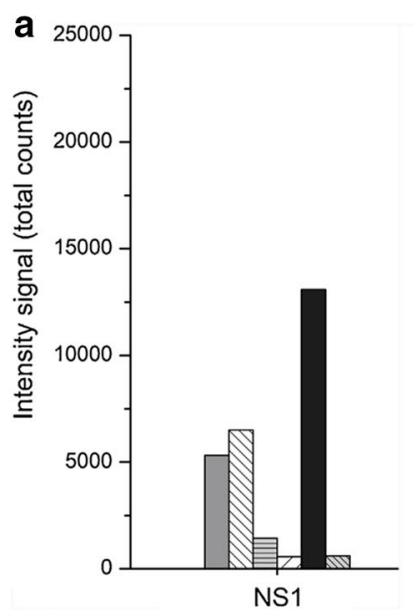

b
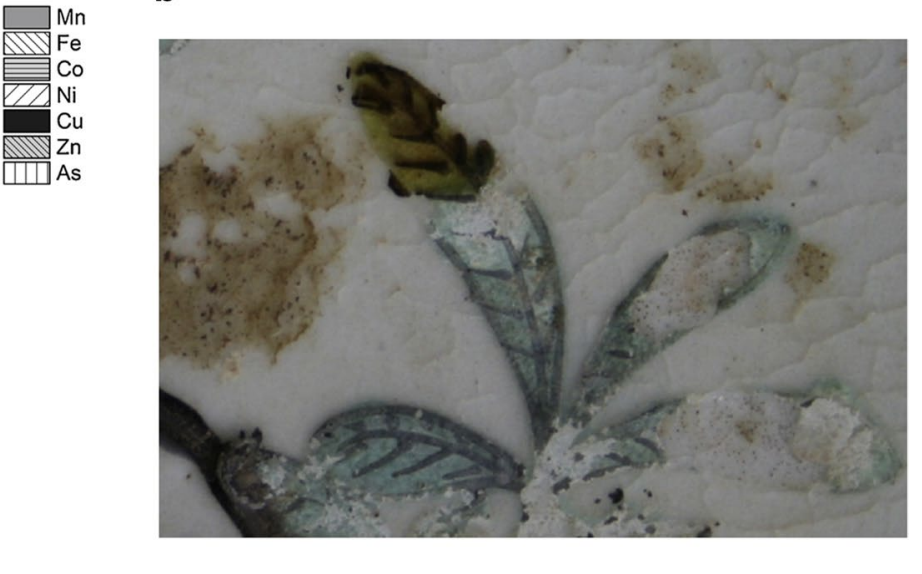

Fig. 10 Naka Shirakawa shard [4], a Schematic of XRF signal of chemical elements recorded on overglaze blue-green, b detail of analysed overglaze blue-green decoration

and low-grade natural-cobalt-ores for underglaze decoration (Fig. 5a, 6a). These findings, along with previous studies [3, 4], fully reveal that even though the Japanese had been exposed to European materials from the late 16 th century, they didn't succeed in mastering the technology needed to reproduce them until the early twentieth century. This further explains why the very limited use of the scarce and expensive lead-based yellows during the Momoyama and early Edo periods suddenly stopped after the final expulsion of all Christians and Jesuits in 1639. The Japanese were still in the earliest stage of enamel-firing experimentation and therefore needed a new chromophore to replace the unavailable Jesuitrelated yellows (lead antimonate and lead-tin yellows). Yellow was the most difficult color to fix for Arita potters [70] and the issue was resolved by means of the cheaper and easier-to-fire iron yellow, likely through Chinese supervision. But the practice of replacing imported European materials of unknown technology with Chinese pigments could not be successfully carried out in the case of smalt. The Japanese were not capable of reproducing the same coloring effect with any of the materials available to them at the time, locally or from China. This is firmly demonstrated by a previous study by Montanari et al. [4]: the polychrome decorated shard (1640-1650) excavated at the Naka-Shirakawa kiln-site (Fig. 10a, b) reveals the attempt to use a low-grade cobalt ore imported from China (commonly employed for underglaze blue decoration) to achieve an overglaze blue-green effect. The attempt failed as the low-grade cobalt ore was unsuitable for overglaze decoration. It becomes undoubtedly clear that as soon as the Jesuits left the country in 1639, the technology to obtain smalt could not be reproduced, and the failed Naka Shirakawa attempt testifies to the tireless effort by Arita potters to find a way of replacing the imported blue material. Potters could not succeed in that task, and were therefore forced to keep relying on imports from Europe. Furthermore, the Naka-Shirakawa shard bears a Fe-based yellow enamel. The presence of both the 'experimentally-failed' overglaze blue-green enamel and the Fe-based yellow enamel on the same shard testifies to the frantic situation Arita potters were facing in the earliest stage of polychrome porcelain production right after Europeans had been expelled from the country in 1639. The shard is offering a glimpse of the period that followed immediately after the total closure of the country around the early 1640s: Japanese potters had managed to replace the Jesuit-related yellow materials with the iron yellow, but could not replace the smalt needed for overglaze blue decoration as it wasn't available in China at the time. Therefore they had to rely entirely on imports by the Dutch, the only Europeans allowed to trade with Japan during the Tokugawa Shogunate. Trade of ceramic materials and development of production techniques became the major factors impacting the competition between potters. The profitable market for enameled wares became the aim of Arita kilns as well as their fierce battleground.

To conclude this part, the results demonstrate that in the late Meiji period (1868-1912), as soon as European presence became relevant once again in the country, contrary to the Edo period, Japanese potters finally managed, for the first time, to establish their own production of antimony yellow and synthetic blue materials. The main difference between the closed country policy of the Edo period and the Meiji policy of strong westernization is 
that the latter led to the establishment of a full-fledged, state-of-the-art industry that enabled Japan to become, once again after 400 years, the hub for European materials and technology in the Far East.

\section{Ready-to-use pigments in the twentieth century: from Europe to Japan and China}

The scientific evidences also confirm the suggestions by Kerr, Wood and Watt $[7,43,71]$ regarding the replacement of Jingdezhen overglaze and underglaze materials with newly developed and ready-to-use pigments imported from France, Germany and Japan in the early twentieth century. In particular, Watt reports the practice at Jingdezhen of mixing natural low-grade Chinese cobalt ores with newly developed synthetic blue pigments in the early twentieth century [71]. The technology transfer appears very clear on the basis of our results: shard \#7 (Fig. 5a) reveals that such practice started in Arita in the late nineteenth century and then spread to Jingdezhen, when the new Japanese-made pigments became an important part of the trade with China in the early twentieth century. Further confirmation comes from the Sb$\mathrm{Cu}$ green enamel detected on shard \#11 (Fig. 7b).

Takamatsu also describes the preparation of blue enamels by listing the reagents involved in the process: he basically tells us that the imported ready-to-use material Hanakonjo was embedded into a $\mathrm{Pb}-\mathrm{Si}-\mathrm{K}$ matrix (a mixture of Shiratama, Tonotsuchi and Hinookaseki) [31]. This further confirms that the Japanese practice of using imported blue pigments from Europe for paintings and ceramics had not changed since the first encounter with the Jesuits in the late sisteenth century. The results presented for shard \#9 and a modern high artistic value cup further prove this continued practice (Fig. 6a, b).

Shard \#9 therefore offers a clear instance of the shift from the smalt-based recipe to the newly developed Cobased synthetic ones: the XRF spectrum shows a compound of $\mathrm{Co}$ and $\mathrm{Zn}$ (Fig. 7a). Such composition is in perfect agreement with the recipe published in 1869 by Thomas Salter in Field's Chromatography or Treatise on Colours and Pigments as Used by Artists [66]. The author lists a Zinc-Cobalt Blue saying that "... For tinting porcelain...it is admirably adapted, imparting thereto a very pure dark blue of extraordinary beauty". Charles-Ernest Guignet further describes in La céramique ancienne et moderne (1899) the effects that the incorporation of $\mathrm{Zn}$ in the blue recipe allows to achieve: “... For sky blues, add zinc oxide...so that the mixture takes on a tone closer to pure blue".

\section{Conclusions}

The analytic results reported here demonstrate how the study of ceramic enamels may provide valuable information not only on the history of porcelain production, but also on materials employed in Asian painting and printing traditions. We have demonstrated how the long-thought exclusive Chinese influence on Japan, especially on ceramics and paintings, was only one aspect of the Japanese technological development of coloring agents. The arrival of Europeans in 1543 triggered a privileged exchange that enabled Japan to become the first hub of European technology in the Far East, thus reversing, for the first time, the centuries-old predominance of China as the main actor in the spread of western culture throughout Asia. The new evidence confirms that the pattern of influence established by the Jesuits in the late 16th century laid the foundation for a new and independent Japanese cultural development. Such development will strongly influence China in the late nineteenth and twentieth centuries. Extensive experimentation with new synthetic pigments and enamels imported from the Old Continent will mark this extraordinary process of Japanese innovation. However, the two traditions will be distinguished by the extensive use of smalt in Japan as opposed to its very limited use in Chinese paintings, as well as in Chinese ceramic production before the eighteenth century.

The new evidences reveal that synthetic pigments started to be produced in Japan in the twentieth century on the basis of European original recipes. Such pigments will also be exported to China for porcelain decoration. Japan, as occurred four centuries earlier with the Jesuits, became once again the hub for western material circulation in the Far East.

Moreover, Raman results have demonstrated, for the first time on Far-Eastern porcelains, that the shift of the $\mathrm{Pb}$ mode of the $\mathrm{A}_{2} \mathrm{O}^{\prime}$ lattice of lead antimonate yellow (Naples Yellow) provides important information on the firing temperature for enamel decoration. Such characteristic, along with its chemical composition, enables the identification of the area of origin and period of manufacture of the yellow enamel.

\author{
Abbreviations \\ EDXRF: Energy-dispersive X-ray fluorescence; XRF: X-ray fluorescence. \\ Acknowledgements \\ We would like to thank Mr. Yoshihisa Tsuruta. \\ Authors' contributions \\ The research project was conceived by RM, who also prepared the manu- \\ script. The shards were selected by NM and RM. The analyses were carried out \\ by RM, MFA, SS. The results were interpreted by RM, MFA, PhC, and CP. PhC \\ and $C P$ also revised the manuscript. All authors read and approved the final \\ manuscript.
}




\section{Funding}

Non applicable.

\section{Availability of data and materials}

All data is available upon request.

\section{Competing interests}

The authors declare that they have no competing interests.

\section{Author details}

${ }^{1}$ Independent Researcher, Expert Witness, Rome, Italy. ${ }^{2}$ Arita Museum of History, 1-4-1, Izumiyama, Arita-cho, Nishimatsuura-Gun, Saga, Japan. ${ }^{3}$ Sorbonne Université, CNRS, MONARIS, 4 Place Jussieu, C49, 75005 Paris, France. ${ }^{4}$ S.T.ArtTest, Via Stovigliai, 88, 93015 Niscemi, CL, Italy. ${ }^{5}$ University of Tuscia, Laboratory of Diagnostics and Materials Science, Largo dell'Università, 01100 Viterbo, Italy.

Received: 13 January 2020 Accepted: 12 May 2020

Published online: 25 May 2020

\section{References}

1. Kôji O. Recent discoveries from archaeological excavations at Edo castle: Re-examining porcelain made in Edo-period Japan. In:Transaction of the Oriental Ceramic Society Society, editor. London: 2013-2014. p. 29-40.

2. Kôji O. Jiki_Porcellana Giapponese tra Oriente ed Occidente 1610-1760. Milano: Electa; 2004.

3. Montanari R, Alberghina MF, Casanova Municchia A, Massa E, Pelagotti A, Pelosi C, Schiavone S, Sodo A. A polychrome Mukozuke (1624-1644) porcelain offers a new hypothesis on the introduction of European enameling technology in Japan. J Cult Herit. 2018;32:232-7.

4. Montanari R, Murakami N, Alberghina MF, Pelosi C, Schiavone S. The Origin of overglaze-blue enameling in Japan: new discoveries and a reassessment. J Cult Herit. 2019;37:94-102.

5. 神庭信幸, 小島道裕, 横島文夫, 坂本 満,「マリア十五玄義図」の調 査, 京都大学所蔵. 1998 (Research on the "Painting of the Madonna with the Infant Jesus and Her Fifteen Mysteries", in Japanese).

6. Duk-Hee K. Western-Style Painting in Japan - Adaptation and Assimilation. Tokyo: Sophia University Press; 2008.

7. Kerr R, Wood N. Science and Civilisation in China: Volume 5, Chemistry and Chemical Technology, Part 12, Ceramic Technology. Cambridge: Cambridge University Press; 2004.

8. Curtis EB. European contributions to the Chinese glass of the early Qing period. J Glass Stud. 1993;35:91-101.

9. Giannini R, Freestone IC, Shortland AJ. European cobalt sources identification in the production of Chinese Famille Rose porcelain. J Archaeol Sci. 2016;80:27-36.

10. Colomban PH, Zhang Y, Zhao B. Non-invasive Raman analyses of huafalang and related porcelain wares. Searching for evidence for innovative pigment technologies. Ceram Int. 2017;43(15):12079-88.

11. NHK Publishing Inc. NHK 歴史ドキュメント6. Tokyo: NHK Publishing Inc; 1987 (in Japanese).

12. NHK promotion. Via Orientalis—Exhibition catalogue. Tokyo: NHK promotion; 1993.

13. Rosi F, Manuali V, Grygar T, Bezdicka P, Brunetti BG, Sgamellotti A, Burgio L, Seccaroni C, Miliani C. Raman scattering features of lead pyroantimonate compounds: implication for the non-invasive identification of yellow pigments on ancient ceramics. Part II. In situ characterisation of Renaissance plates by portable micro-Raman and XRF studies. J Raman Spectrosc. 2011;42(3):407-14.

14. Cartechini L, Rosi F, Miliani C, D’Acapito F, Brunetti BG, Sgamellotti A. Modified Naples yellow in Renaissance majolica: study of Pb-Sb-Zn and $\mathrm{Pb}$-Sb-Fe ternary pyroantimonates by $\mathrm{X}$-ray absorption spectroscopy. J Anal Atom Spectrom. 2011;26(12):2500-7.

15. Chiarantini L, Gallo F, Rimundi V, Benvenuti M, Costagliola P, Dini A. Early Renaissance production recipes for Naples Yellow pigment: a mineral and lead isotope study of Italian Majolica from Montelupo (Florence). Archaeometry. 2015;57(5):879-96.

16. Sakellariou K, Miliani C, Morresi A, Ombelli M. Spectroscopic investigation of yellow majolica glazes. J Raman Spectrosc. 2004;35(1):61-7.
17. Kırmızı B, Colomban PH, Blanc M. On-site analysis of Limoges enamels from sixteenth to nineteenth centuries: an attempt to differentiate between genuine artefacts and copies. J Raman Spectrosc. 2010;41(10):1240-7.

18. Dik J, Hermens E, Peschar R, Schenk H. Early production recipes for lead antimonate yellow in Italian art. Archaeometry. 2005;47(3):593-607.

19. Agresti G, Baraldi P, Pelosi C, Santamaria U. Yellow pigments based on lead, tin and antimony: ancient recipes, synthesis, characterization and hue choice in artworks. Color Res Appl. 2016:41(3):226-31.

20. Neri E, Morvan C, Colomban PH, Guerra MP, Prigent V. Late Roman and Byzantine Mosaic opaque "Glass-ceramics" Tesserae ( $5^{\text {th }}-9$ th century). Ceram Int. 2016;42(16):18859-69.

21. Caggiani MC, Colomban PH, Mangone A, Valloteau C, Cambon P. Mobile Raman spectroscopy analysis of ancient enamelled glass masterpieces. Anal Methods. 2013;5:4345-54.

22. Kırmızı B, Gokturk H, Colomban PH. Colouring agents in the pottery glazes of Western Anatolia: a New evidence for the use of Naples Yellow pigment variations during the late Byzantine Period. Archaeometry. 2015;57(3):476-96.

23. Vandenborre MT, Husson E, Chatry JP, Michel D. Rare-earth titanates and stannates of pyrochlore structure; vibrational spectra and force fields. J Raman Spectrosc. 1983;14(2):63-71.

24. Glerup $M$, Nielsen OF, Poulsen FW. The structural transformation from the pyrochlore structure, $A(2) B(2) O(7)$, to the fluorite structure, $A O(2)$, studied by Raman spectroscopy and defect chemistry modeling. J Sol State Chem. 2001;160(1):25-32.

25. Pereira M, de Lacerda-Aroso T, Gomes MJM, Mata A, Alves LC, Colomban $\mathrm{PH}$. Ancient Portuguese Ceramic Wall Tiles («Ajulejos»): characterization of the Glaze and Ceramic Pigments. J Nano Research. 2009;8:79-88.

26. Maggetti M, Neururer C, Rosen J. Antimonate opaque glaze colours from the Faience manufacture of le Bois d'Épense (19th century, northeastern France). Archaeometry. 2009;51(5):791-807.

27. Sandalinas F, Ruiz-Morino S. Lead-tin-antimony yellow historical manufacture, molecular characterization and identification in seventeenthcentury Italian paintings. Stud Conservation. 2004;49(1):41-52.

28. Rosi F, Manuali V, Miliani C, Dacapito F, Brunetti BG, Sgamellotti A. Raman scattering features of lead pyroantimonate compounds. Part I: XRD and Raman characterization of $\mathrm{Pb}_{2} \mathrm{Sb}_{2} \mathrm{O}_{7}$ doped with tin and zinc. J Raman Spectrosc. 2009;40(1):107-11.

29. Cartechini L, Rosi F, Miliani C, Brunetti BG, Sgamellotti A, Grygar T, Hradil D. Modified Naples yellow in Renaissance majolica: study of Pb-Sb-Zn and $\mathrm{Pb}$-Sb-Fe ternary pyroantimonates by $\mathrm{X}$-ray absorption spectroscopy. J Anal Atom Spectrosc. 2011;26(12):2500-7.

30. Colomban PH, Arberet L, Kırmızı B. On-site Raman analysis of 17th and 18th century Limoges Enamels: implications on the European cobalt sources and the technological relationship between Limoges and Chinese Enamels. Ceram Int. 2017;43(13):10158-65.

31. Takamastu T. On Japanese pigments. Tokyo: Department of Science in Tokio Daigaku; 1878.

32. Gettens RJ, Stout GL. Painting materials: a short encyclopedia. Dover Publications; 2011.

33. Simsek G, Colomban PH, Wong S, Zhao B, Rougeulle A, Liem NQ. Toward a fast non-destructive identification of pottery: the sourcing of 14th-16th century Vietnamese and Chinese ceramic shards. J Cult Herit. 2015;16(2):159-72.

34. Colomban PH, Sagon G, Le Quang H, Quang Liem N, Mazerolles L. Vietnamese (15th century) blue-and-white, tam thai and "luster" porcelains/ stoneware: glaze composition and decoration techniques. Archaeometry. 2004:46(1):125-36.

35. Colomban PH. Rocks as blue (green and black) pigments/dyes of glazed pottery and enamelled glass artefacts - the potential of Raman microscopy. Eur Mineral J. 2013;25(5):863-79.

36. Tite MS. The production technology of Italian maiolica: a reassessment. J Archaeol Sci. 2009;36:2065-80.

37. Dik J, Tichelaar FD, Goubitz K, Peschar R, Schenk H. 19th century Naples yellow re-examined. Zeitschrift fur Kunsttechnologie und Konservierung. 2002;16:291-306.

38. FitzHugh EW, Winter J, Leona M. Pigments in later Japanese paintings. Washington D.C: Smithsonian Institution, Freer Gallery of Art; 2003. 
39. Colomban PH, Sagon G, Faurel X. Differentiation of antique ceramics from the Raman spectra of their coloured glazes and paintings. J Raman Spectrosc. 2001;32(5):351-60.

40. Vandenborre MT, Husson E. Comparison of the force field in various pyrochlore families. I. The A2B2O7 oxides. J Solid State Chem. 1983;50(3):362-71.

41. Vandenborre MT, Husson E. Comparison of the force field in various pyrochlore families. II. Phases presenting structural defects. J Solid State Chem. 1984:53(2):253-9.

42. Miao J, Jung B, Mu D. Identification and differentiation of opaque Chinese overglaze yellow enamels by Raman spectroscopy and supporting techniques. Archaeometry. 2010;52(1):46-155.

43. Wood N. Chinese glazes: their origins, chemistry, and recreation. University of Pennsylvania Press; 1999.

44. Kırmızı B, Colomban PH, Quette B. On-site analysis of Chinese Cloisonné enamels from fifteenth to nineteenth centuries. J Raman Spectrosc. 2010;41(7):780-90.

45. Henderson J, Tregear M, Wood N. The technology of sixteenth- and seventeenth-century Chinese Cloisonné enamels. Archaeometry. 1989:31(2):133-46.

46. Kerr R. Chinese Ceramics_Porcelain of the Qing Dynasty 1644-1911. London: V\&A Publishing; 1986

47. Impey O. The early porcelain kilns of Japan. Oxford: Clarendon Press; 1996.

48. Fitski M. Kakiemon porcelain — a handbook. Leiden: Leiden University Press; 2011.

49. Volker T. The Japanese porcelain trade of the Dutch East India Company after 1683. Leiden: E.J. Brill; 1959.

50. Zhang F, Zhang Z. Ancient Chinese overglaze colours. J Chin Ceram Soc. 1980;8:339-51 (in Chinese).

51. He W, Xiong Y. A study of enamels on Chinese Porcelain of Qing Dynasty. Science and Technology of Ancient Ceramics, 6: proceedings of the International Symposium (ISAC'05), 2005. p. 446-451 (in Chinese).

52. Domoney K, Shortland AJ, Khun S. Characterization of 18th-century Meissen Porcelain using SEM-EDS. Archaemotry. 2012;54(3):454-74.

53. Cesaratto A, Luo Y, Smith II HD, Leona M. A timeline for the introduction of synthetic dyestuffs in Japan during the late Edo and Meiji periods. Heritage Science. 2018. p. 6-22.

54. Oka S, Miura S, Hayakawa Y, Miyakoshi T. Scientific analysis used in the treatment of the map of the world and famous cities screen and resulting new perspectives on the paintings, scientific research on the pictorial arts of Asia. London: Archetype Books; 2005. p. 16-20.

55. Tokyo National Research Institute for Cultural Properties. Report on an optical study of "Western Kings on Horseback Screens". Tokyo: Tokyo National Research Institute for Cultural Properties; 2015 (in Japanese).

56. Berrie $\mathrm{BH}$, Leona M, McLaughlin R. Unusual pigments found in a painting by Giotto (c. 1266-1337) reveal diversity of materials used by medieval artists. Herit Sci. 2016;4:1.

57. Viti C, Borgia I, Brunetti B, Sgamellotti A, Mellini M. Microtexture and microchemistry of glaze and pigments in Italian Renaissance pottery from Gubbio and Deruta. J Cult Herit. 2003;4:199-210.

58. Casadio F, Bezur A, Domoney K, Eremin K, Lee L, Mass JL, Shortland A, Zumbulyadis N. X-ray fluorescence applied to overglaze enamel decoration on eighteenth- and nineteenth-century porcelain from central Europe. Vienna: Int Inst Conserv Hist Artist Works; 2012
59. Borgia I, Brunetti B, Mariani I, Sgamellotti A, Cariati F, Fermo P, Mellini M, Viti C, Padeletti G. Heterogeneous distribution of metal nanocrystals in glazes of historical pottery. Appl Surf Sci. 2002;185:206-16.

60. Pérez-Arantegui J, Resano M, García-Ruiz E, Vanhaecke F, Roldàn C, Ferrero J, Coll J. Characterization of cobalt pigments found in traditional Valencian ceramics by means of laser ablation-inductively coupled plasma mass spectrometry and portable X-ray fluorescence spectrometry. Talanta. 2008;74(5):1271-80.

61. Magurn BW. Daitoku Myō-Ō a Japanese Buddhist Deity. Cambridge: Bulletin of the Fogg Art Museum, Harvard Art Museums. 1942;10(1):4-23.

62. Roy A, editor. Artists'Pigments - a handbook of their history and characteristics, vol. 2. London: National Gallery of Art, Archetype Publications; 1993.

63. Shimoyama S, Noda Y. Portable X-Ray Fluorescence spectrometer containing low-level radioisotope and its application to the non-destructive analysis of inorganic colorants used for the traditional Japanese votive picture. Bunseki Kagaku. 2000;49(12):1015-21 (in Japanese).

64. Colomban PH, Ambrosi F, Ngo A, Lu T, Feng X, Chen S, Choi C. Comparative analysis of Wucai Chinese porcelains using mobile and fixed Raman microspectrometers. Ceram Int. 2017;43(16):14244-56.

65. Colomban PH, LuTA, Milande V. Non-invasive on-site Raman study of blue decorated early soft-paste porcelain: the use of arsenic-rich (European) cobalt ores-Comparison with huafalang Chinese porcelains. Ceram Int. 2018:44(8):9018-26.

66. Eastaugh N, Walsh V, Chaplin T, Siddall R. Pigment compendium: a dictionary and optical microscopy of historic pigments. Routledge; 2008.

67. Shimoyama S, Matsui H. Research on the process of introduction of prussian blue into ukiyo-e prints using the RI fluorescent $\mathrm{X}$-ray nondestructive analysis technique. Proceedings of the 7th symposium on JAERI's Reimei Research Program; 2004 (in Japanese).

68. Hayakawa Y, Ota A. Blue-colored Materials Used in Doshoku Sai-e by Ito Jakuchu. Sci Conserv. 2010;49:131-7 (in Japanese).

69. Kato M, Tanzawa Y, Hirai S, Hayakawa Y, Miura S. Material Analysis of "Kaishunsai Paints" Belonging to the Nabeshima Family. Sci Conserv. 2007;46:61-74 (in Japanese).

70. Nishida H. Japanese Export Porcelain During the 17th and 18th Century. Oxford: Oxford University; 1974. (D. Phil. dissertation).

71. Watt JCY. Notes on the Use of Cobalt in Later Chinese Ceramics. Ars Orientalis. 1979;11:63-85.

72. Jenyns S. Japanese porcelain. London: Faber and Faber; 1965

73. Impey O, Kakiemon. In: Transaction of the Oriental Ceramic Society Society, editor. London: 2003-2004;68: p. 1-14

74. Impey O. Japanese export porcelain: catalogue of the collection of the Ashmolean Museum, Oxford. Leiden: Hotei Publishing; 2002.

75. Jörg CJA. Fine and curious: Japanese export porcelain in Dutch collections. Leiden: Hotei Publishing; 2003.

76. Nagatake T. Classic Japanese Porcelain_Imari and Kakiemon. Tokyo: Kodansha International; 2003.

77. Winter J. East Asian paintings - materials, structures and deterioration mechanisms. London: Archetype Publications Ltd; 2008.

\section{Publisher's Note}

Springer Nature remains neutral with regard to jurisdictional claims in published maps and institutional affiliations. 